\title{
Optimization, Purification and Physicochemical Characterization of Curdlan Produced by Paenibacillus sp. Strain NBR-10
}

\author{
Mohamed Helal El-Sayed ${ }^{1,2 *}$, Hussam H. Arafat ${ }^{1,3}$, \\ Islam A. Elsehemy ${ }^{4}$ and Mona Basha ${ }^{5}$ \\ ${ }^{1}$ Department of Biology, Faculty of Science and Arts, \\ Northern Border University (Rafha), Kingdom of Saudi Arabia \\ ${ }^{2}$ Department of Botany and Microbiology, Faculty of Science, Al-Azhar University, Cairo, Egypt. \\ ${ }^{3}$ Department of Botany and Microbiology, Faculty of Science, \\ Minia University, Minia City- 61519, Egypt. \\ ${ }^{4}$ Department of Natural and Microbial Products Chemistry, Division of Pharmaceutical and Drug Industries \\ Research, National Research Centre, Dokki, Cairo, Egypt. \\ ${ }^{5}$ Pharmaceutical Technology Department, National Research Centre, Dokki, Cairo, Egypt.
}

http://dx.doi.org/10.13005/bbra/2113

(Received: 09 April 2016; accepted: 19 May 2016)

\begin{abstract}
In recent years, significant progress has been done to discover a novel microbial exopolysaccharides that possess novel and highly functional properties. During our screening program for curdlan producing bacteria, 35 bacterial strains were isolated from 15 sandy soils collected from Rafha governorate, Northern Border region, Saudi Arabia. Among them isolate, NBR-10 was selected for its promising ability for curdlan production. The selected isolate was identified based on methods or results mentioned in this paper as Paenibacillus sp. For enhancing the curdlan yield produced by Paenibacillus sp. NBR-10, different culture conditions and medium compositions were optimized. It was found that, the maximum yield was obtained at $35{ }^{\circ} \mathrm{C}$, initial $\mathrm{pH} 7$ after $48 \mathrm{~h}$ of incubation. Also different carbon and nitrogen sources were used to improve the curdlan yield, it was indicated that sucrose and yeast extract were the best carbon and nitrogen sources respectively. Generally, optimization of the different parameters was approximately duplicated the curdlan yield from $2.34 \mathrm{~g} / \mathrm{l}$ to $4.82 \mathrm{~g} / \mathrm{l}$. The precipitated curdlan dissolved in $2 \mathrm{M} \mathrm{NaOH}$ exhibited high affinity to gel formation. Analysis of FTIR, ${ }^{1} \mathrm{H}$ NMR and ${ }^{13} \mathrm{C}$ NMR spectra proved that the produced polymer by Paenibacillus sp. NBR-10 has $\beta$-(1-3)-D-glucan (curdlan) structure.
\end{abstract}

Key words: Curdlan, Paenibacillus sp., Optimization, Characterization.

In recent years, significant progress has been done to discover a novel microbial exopolysaccharides that possess novel and highly functional properties ${ }^{1}$. Curdlan is a polysaccharide composed exclusively of beta -1,3-linked glucose residues. $\beta$-(1-3)-D-glucans are normally present in cell walls and membranes of fungi, yeasts, algae, bacteria and higher plants, however only in the case of bacteria this polymer is produced

\footnotetext{
* To whom all correspondence should be addressed. Tel.: 00966545905650;

E-mail: m_helal2007rm@yahoo.com
}

extracellularly under nutrient deficient conditions ${ }^{2,3}$. Initial studies recorded that, exopolysaccharide curdlan is produced from Gram negative bacteria Agrobacterium and Alcaligenes species, but recently other reports recorded production of curdlan from Gram positive bacteria as in species of Bacillus ${ }^{4}$, Cellulomonas ${ }^{5}$ and Paenibacillus ${ }^{6,7}$.

Exopolysaccharides from Paenibacillus spp. were only discovered in the past ten years. The genus Paenibacillus consists of more than 89 species of facultative anaerobes, neutrophilic, endospore forming, periflagellated heterotrophic and low G + C Gram +ve bacilli, which were 
originally included within the genus Bacillus and then reclassified as a separate genus ${ }^{8}$. Bacteria belonging to this genus have been detected in a variety of environments such as soil, rhizospheres, water, vegetable matter, insect larvae and forage, as well as clinical samples ${ }^{9}$.

Paenibacillus species produced a wide variety of different exopolysaccharides with diverse biotechnological and physiological functions. Paenibacillus species exopolysaccharides have also attracted great interest because of their biotechnological potential in wastewater treatment and different industrial processes ${ }^{6}$. Thorough studies on the production and applications of Paenibacillus spp., exopolysaccharides have shown that there is a growing interest in using Paenibacillus spp. exopolysaccharides as biomaterials; extensive research has been performed, leading to a large number of publications in recent years ${ }^{10}$.

Curdlan polymer gained its economical importance after gellan and xanthan and this became the third microorganism-fermented hydrocolloid. Curdlan is insoluble in water and alcohols but it is soluble in alkaline solutions and DMSO. One of the unique properties of this polymer is that it is capable of forming irreversible and thermostable gel once after heating to $80^{\circ} \mathrm{C}$. These properties gained this polymer their importance. Curdlan have numerous applications in the field of medicine, pharmaceutical and food industries ${ }^{11}$. Curdlan is used as stabilizer in jelly foods, bio-thickener for noodles and as immobilizing supports, also it is used as a texturizer in meat, dairy and baking industries owing to its unique properties (tasteless, colorless and odorless) and water holding capacity ${ }^{12}$. Thus, to meet the great demand for curdlan in different applications, attempts have been made to get a new microbial source and optimize the fermentation conditions for curdlan production. The present study was had an objective to isolate and characterize the exopolysaccharide produced by soil isolated Paenibacillus sp. NBR-10 under the optimized production conditions.

\section{MATERIALSANDMETHODS}

\section{Isolation of Curdlan Producing Bacteria}

Fifteen sandy soils obtained from three different localities in Rafha governorate, Northern Border region, Saudi Arabia were collected in sterile plastic pages and kept in an icebox containing ice packs until reached to the laboratory. Ten grams of the air dried samples were added to $100 \mathrm{ml}$ of sterile saline solution and agitated at $100 \mathrm{rpm}$ for $10 \mathrm{~min}$; $0.1 \mathrm{ml}$ of the supernatant was transferred to $0.9 \mathrm{ml}$ of sterile saline and serial dilutions $\left(10^{-1}\right.$ to $\left.10^{-6}\right)$ were prepared. $100 \mu \mathrm{l}$ of each dilution was added and distributed on specific media containing aniline blue and Congo red dyes ${ }^{13}$, the medium was consisted of (g/l): sucrose (20.0), yeast extract (5.0), dye (0.05) and agar (20.0) at $\mathrm{pH}$ 7.0. Inoculated plates were incubated for $48 \mathrm{~h}$ at $35{ }^{\circ} \mathrm{C}$, colonies showing intense blue or red color were streak purified at least three times on the same agar medium and kept at $4{ }^{\circ} \mathrm{C}$ for further studies. The purified isolates were subjected for screening to determine the most potent isolate.

\section{Preparation of Inoculums}

A loop full of $24 \mathrm{~h}$ old agar culture of isolate, NBR-10 (the most promising isolate) was first grown in $10 \mathrm{ml}$ nutrient broth for $18 \mathrm{~h}$ at $35^{\circ} \mathrm{C}$. Optical density (OD) of the bacterial culture was adjusted by using sterile distilled water to become 0.50 at $620 \mathrm{~nm}$.

\section{Screening for Best Production Media}

Eight fermentation media were used to evaluate the production of curdlan in submerged fermentation conditions which was carried out in $250 \mathrm{ml}$ Erlenmeyer flasks containing $50 \mathrm{ml}$ medium, autoclaved at $121{ }^{\circ} \mathrm{C}$ for $20 \mathrm{~min}$, inoculated with $1 \%(\mathrm{v} / \mathrm{v})$ of $18 \mathrm{~h}$ old inoculum. The inoculated flasks were incubated for $96 \mathrm{~h}$ at $35^{\circ} \mathrm{C}, \mathrm{pH} 7$ under shaking at $200 \mathrm{rpm}$. At the end of incubation period, the culture was centrifuged for $20 \mathrm{~min}$ at $8000 \mathrm{rpm}$ and the cell free supernatant was taken for curdlan investigation. Experiments were carried out in triplicate and results reported are the average value with standard deviations.

\section{Optimization of Curdlan Production}

The medium composition and culture conditions were examined to optimize curdlan production by Paenibacillus $s p$. NBR-10; glucose in the basal medium was replaced with $50 \mathrm{~g} / \mathrm{l}$ equivalent weight of different carbon sources; sucrose, fructose, lactose and glycerol. Studies also were carried out to evaluate the influence of addition of different nitrogen sources; yeast extract, peptone, ammonium nitrate $\left(\mathrm{NH}_{4} \mathrm{NO}_{3}\right)$, ammonium 
chloride $\left(\mathrm{NH}_{4} \mathrm{Cl}\right)$ and potassium nitrate $\left(\mathrm{KNO}_{3}\right)$. Urea in the basal medium was replaced with different nitrogen sources added separately to the fermentation medium at equivalent weight represents $0.3 \mathrm{~g} / \mathrm{l}$ of nitrogen $(\mathrm{w} / \mathrm{v})$, the inoculated flasks were incubated for $96 \mathrm{~h}$ at $35^{\circ} \mathrm{C}, \mathrm{pH} 7$ under shaking at $200 \mathrm{rpm}$.

\section{Optimization of Environmental Parameters}

To study the influence of initial $\mathrm{pH}$ of the medium on curdlan production, the initial $\mathrm{pH}$ of the medium was set at different $\mathrm{pH}$ values ranged from $4.0-8.0$ using $1 \mathrm{~N} \mathrm{NaOH}$ or $\mathrm{HCl}$. The experiments were conducted to evaluate the effect of incubation temperature on curdlan production, for which fermentation was carried out at 25, 30, 35 and $45^{\circ} \mathrm{C}$. In order to select the suitable volume of the fermentation medium for curdlan production by isolate NBR-10, flasks were prepared containing 25, 50, 75 and $100 \mathrm{ml}$ of fermentation medium. Curdlan production was tested during $96 \mathrm{~h}$ in order to detect the optimum incubation time.

\section{Analytical Methods}

\section{Estimation of Curdlan Production and Cell} Biomass

The yield of curdlan gum and biomass production was estimated according to the reported protocol of Lee et al. ${ }^{3}$ with little modification: $50 \mathrm{ml}$ of sample was mixed with $150 \mathrm{ml}$ of $0.5 \mathrm{~N} \mathrm{NaOH}$ solutions. The mixture was kept for $12 \mathrm{~h}$ at room temperature, to remove degraded bacterial cells, the mixture then centrifuged at $8000 \mathrm{rpm}$ for $20 \mathrm{~min}$ and the supernatant was removed by centrifugation. The aliquot washed two times with distilled water and the cell mass was filtered through Whatman filter paper and then dried at 70 ${ }^{\circ} \mathrm{C}$ for $24 \mathrm{~h}$. The weight of the dried cells was measured. The supernatant was neutralized with $3 \mathrm{~N} \mathrm{HCl}$ to pH 5-7 after keeping the mixture at 2-8 ${ }^{\circ} \mathrm{C}$ overnight then centrifugation at $8000 \mathrm{rpm}$ to obtained curdlan, washed twice with de-ionized water to remove salts. Obtained curdlan was dialyzed at $4{ }^{\circ} \mathrm{C}$ for 2 days in de-ionized water and lyophilized to give pure material.

\section{Characterization of Curdlan Gum \\ Physical Characters}

Color, solubility, solubility in alkali, gel formation and perception formation with cupric tartrate were studied. $5 \mathrm{ml}$ of sulfuric acid add to 10 $\mathrm{ml}$ of a $2 \%$ aqueous suspension of the sample, after heating in boiling water bath for $30 \mathrm{~min}$ and cool, the mixture neutralized with barium carbonate, the mixture centrifuged at $4000 \mathrm{rpm}$ for $10 \mathrm{~min}$, one $\mathrm{ml}$ of the supernatant was added to $5 \mathrm{ml}$ of hot alkaline cupric tartrate ${ }^{14}$.

\section{Chromatographic Examination}

Curdlan was subjected to acid hydrolysis by dissolving $50 \mathrm{mg}$ of the precipitate in $5 \mathrm{ml}$ of $2 \mathrm{~N}$ sulfuric acid and hydrolyzed at $100^{\circ} \mathrm{C}$ for $5 \mathrm{~h} .50 \mu \mathrm{l}$ of the hydrolysate was loaded onto a paper chromatography and developed in (4:5:3) acetonebutanol-water solvent system. Authentic samples of glucose, galactose, arabinose and xylose were used as a standard. The generated chromatogram was sprayed with $[0.5 \%(\mathrm{w} / \mathrm{v}) \alpha$-naphthol dissolved in $5 \%(\mathrm{v} / \mathrm{v})$ sulfuric acid in ethanol] at $120^{\circ} \mathrm{C}$ for $10 \mathrm{~min}^{7}$.

\section{Chemical Characters}

FT-IR and HNMR spectra were carried out at Micro Analytical Center of Cairo University, Egypt using DMSO-D6 as a solvent, The FT-IR spectra were determined at 400 to $4,000 \mathrm{~cm}^{\prime \prime}$ using a using a PerkinElmer spectrometer (Boston, MA, USA) employing potassium bromide ( $\mathrm{KBr}$ ) disks. $\mathrm{H}^{1}$ NMR and $\mathrm{C}^{13}$ NMR were run on a BRUKER Ultrashield 400 MHz NMR (Varian, USA) ${ }^{12,15}$.

\section{RESULTSAND DISCUSSION}

\section{Isolation of Curdlan Producing Bacteria}

Thirty five bacterial strains (coded NBR1 to NBR-35) were isolated on aniline blue and Congo red containing media among them only ten isolates were bounded with aniline blue and Congo red dyes forming blue-black and red colonies on blue and Congo red media respectively (Figure 1) which may be indicated to the ability of these isolates to produce curdlan. Kim et al. ${ }^{13}$ and Nakanishi et al. ${ }^{16}$ reported that, curdlan bind with Congo red forming a red complex and bind with aniline blue forming a blue complex, but aniline blue is more specific to curdlan more than Congo red, the rate of color complex formation was dependent on the polymer concentration.

Among ten isolates which exhibited positive results on the screened media, isolate NBR-10 was selected as the most isolate produce intense blue color. 
Table 1. Fermentation media used for evaluation of curdlan production by Paenibacillus sp. NBR-10

\begin{tabular}{|c|c|c|c|c|c|c|c|c|}
\hline $\begin{array}{l}\text { Media } \\
\text { Components (g/l) }\end{array}$ & $\begin{array}{l}\text { Medium } \\
(1)^{6}\end{array}$ & $\begin{array}{l}\text { Medium } \\
(2)^{17}\end{array}$ & $\begin{array}{l}\text { Medium } \\
(3)^{4}\end{array}$ & $\begin{array}{l}\text { Medium } \\
(4)^{18}\end{array}$ & $\begin{array}{l}\text { Medium } \\
(5)^{14}\end{array}$ & $\begin{array}{l}\text { Medium } \\
(6)^{19}\end{array}$ & $\begin{array}{l}\text { Medium } \\
(7)^{3}\end{array}$ & $\begin{array}{l}\text { Medium } \\
\qquad(8)^{20}\end{array}$ \\
\hline Glucose & 50.0 & 50.0 & & 50.0 & 20.0 & 20 & 20 & \\
\hline Sucrose & & & 100.0 & & & & & \\
\hline Mannitol & & & & & & & & 4.0 \\
\hline Yeast extract & 1.0 & & & & & & 5.0 & 0.14 \\
\hline Corn steep liquor & & & & & 15 & & & \\
\hline Peptone & & & & & 2.0 & & 5.0 & \\
\hline Urea & & 0.3 & & & & & & \\
\hline$\left(\mathrm{NH}_{4}\right)_{2} \mathrm{HPO}_{4}$ & & & 2.3 & 1.1 & & & & \\
\hline $\mathrm{NH}_{4} \mathrm{Cl}$ & & & & & & 1.5 & & \\
\hline $\mathrm{K}_{2} \mathrm{HPO}_{4}$ & 0.5 & & & 1.7 & & 0.49 & & 0.7 \\
\hline $\mathrm{K}_{2}^{2} \mathrm{PO}_{4}$ & 2.0 & 2 & 1.0 & 1.74 & 2.0 & 1.74 & & 0.9 \\
\hline $\mathrm{FeCl}_{3}$ & 1.0 & 1.0 & & & & 0.024 & & \\
\hline $\mathrm{MnCl}_{2}$ & 1.0 & 1.0 & & & & 0.01 & & \\
\hline $\mathrm{CaCl}_{2}{ }^{2}$ & 1.0 & 1.0 & & & & 0.015 & & \\
\hline $\mathrm{MgSO}_{4}$ & 0.5 & 0.5 & 0.4 & 0.5 & 0.5 & 0.25 & & 0.2 \\
\hline $\mathrm{NaCl}$ & 1.0 & 1.0 & & & & 3.7 & & 0.2 \\
\hline $\mathrm{CaCO}_{3}$ & & & 3.0 & & & & & \\
\hline Curdlan yield (g/l) & 2.030 & 2.342 & ND* & 2.158 & ND & ND & ND & 1.895 \\
\hline Cell biomass (g/l) & 3.509 & 3.024 & 4.392 & 3.892 & 2.96 & 2.87 & 2.58 & 4.542 \\
\hline
\end{tabular}

ND*= Not detected.

Screening for the Best Media for Curdlan Production in Submerged Fermentation conditions

Curdlan production depends markedly on the composition of the culture medium such as carbon, nitrogen contents and inducer compounds ${ }^{16}$. Eight fermentation media (Table 1) were used to evaluate curdlan production by Paenibacillus sp. NBR-10. It was found that, media no 2, 4, 1 \& 8 gave 2.342, 2.158, 2.030 \& 1.895 g/l respectively, while curdlan production not observed on media numbers no 3, 5, 6 \& 7. Also, it was noticed that medium no 8 showed the maximum cell biomass production comparing with other media. Based on these results medium no. 2 was employed as the original medium for optimizing the conditions of curdlan production. Jiang ${ }^{17}$ recorded curdlan production at high level by using the same medium from Alcaligenes faecalis ATCC 31749.

\section{Optimizations of Production Media}

By replacing glucose in the selected medium with different carbon sources and remaining of other contents of the medium, the results indicated that, curdlan production by
Paenibacillus sp. NBR-10 was increased (2.955 g/ l) when the cells were grown in sucrose-containing medium, while other tested carbon sources (fructose, lactose and glycerol) exhibited low levels of curdlan production (Table 2 ). Lee et al. ${ }^{3}$ recorded that, sucrose is the most suitable carbon source for curdlan production by Agrobacterium sp. In contrast, Cui and Qiu ${ }^{4}$ reported, glucose was the most suitable carbon source for curdlan production by Pseudomonas sp. these may be due to the different metabolic pathways of the tested organisms.

Our results exhibited that the best nitrogen source for curdlan production was yeast extract (3.12 g/l) followed by urea (2.950 g/l) while the others nitrogen sources; peptone, $\mathrm{NH}_{4} \mathrm{NO}_{3}$, $\mathrm{NH}_{4} \mathrm{Cl}$ and $\mathrm{KNO}_{3}$ resulted low levels of curdlan production (Table 2). Various studies suggesting that the supplementation of yeast extract to the culture medium was capable of stimulating curdlan production from Agrobacterium sp. ${ }^{21}$, also Kim et al. ${ }^{22}$, noted that curdlan production and cell concentration by Pseudomonas sp. from organic nitrogen source are higher than that of inorganic nitrogen source. Jiang ${ }^{17}$ found that curdlan 


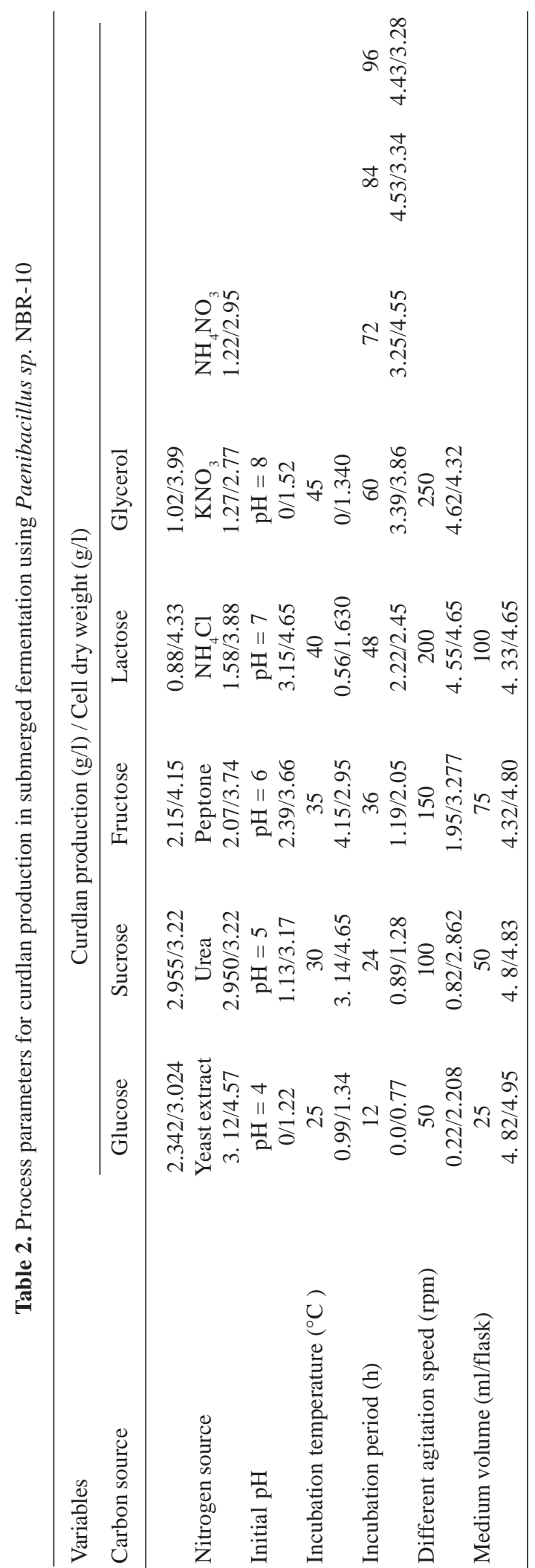

production and biomass accumulation were greater with urea than other nitrogen sources.

\section{Optimization of Environmental Parameters}

$\mathrm{pH}$ value is critical factor affecting all metabolic pathways in the microbial cell. Our results noted that, the optimal $\mathrm{pH}$ value which inducted the high production rate was 7.0 (3. $15 \mathrm{~g} /$ l), lower values ( $\mathrm{pH} 4$ ) and higher values ( $\mathrm{pH} 8.0)$ caused inhibition in curdlan production (Table 2). Lee et al. ${ }^{23}$ found that the optimum $\mathrm{pH}$ value for exopolysaccharides production by Bacillus polymyxa KCTC 8648P was 7.0. However, higher values ( $\mathrm{pH}$ 8.5) caused a decrease in their production while Lee et al. ${ }^{3}$ reported that, maximum curdlan production from Agrobacterium species in batch fermentation was occurred at pH 5.5. Temperature is an environmental parameter affect on the viability and activity of the microbial cell as well as the curdlan production ${ }^{24}$. A result referred to the best incubation temperature was $35^{\circ} \mathrm{C}$ that yielded (4.15 g/l), curdlan production was slightly decreased at $25^{\circ} \mathrm{C}$, while, the curdlan yield was not observed at $45^{\circ} \mathrm{C}$. At lower temperature, the transport of substrate across the cells was suppressed and lower yield of products was attained. At higher temperature, the maintenance energy requirement for cellular growth is high due to thermal denaturation of enzymes of the metabolic pathway $^{25}$.

Paenibacillus sp NBR-10 was incubated for $96 \mathrm{~h}$ and the results showed that the level yield of curdlan increased gradually with increasing the incubation period until it reached the maximum (4.53 $\mathrm{g} / \mathrm{l})$ after $84 \mathrm{~h}$ of the fermentation. These results were similar to that reported by Gummadi and $\mathrm{Kumar}^{26}$, which found maximum curdlan production by Bacillus sp SNC07 was obtained at (70 to $84 \mathrm{~h}$ ) of fermentation. While Rafigh et al. ${ }^{6}$ found that maximum curdlan production for Paenibacillus polymyxa ATCC 21830 was obtained at (96 h) of fermentation. Also, curdlan production increased with the increase of agitation speed as well as aeration, the maximum production rate $(4.62 \mathrm{~g} / \mathrm{l})$ was occurred at $250 \mathrm{rpm}$. Also, curdlan productions had no remarkable change in 25-50 ml recording (4.82 g/l), and slowly decrease if the flask capacity was increased up to $75 \mathrm{ml}$ and more. Under optimized cultural conditions either nutritionally or environmentally, curdlan yield was increased from $2.342 \mathrm{~g} / \mathrm{l}$ to $4.82 \mathrm{~g} / \mathrm{l}$. 

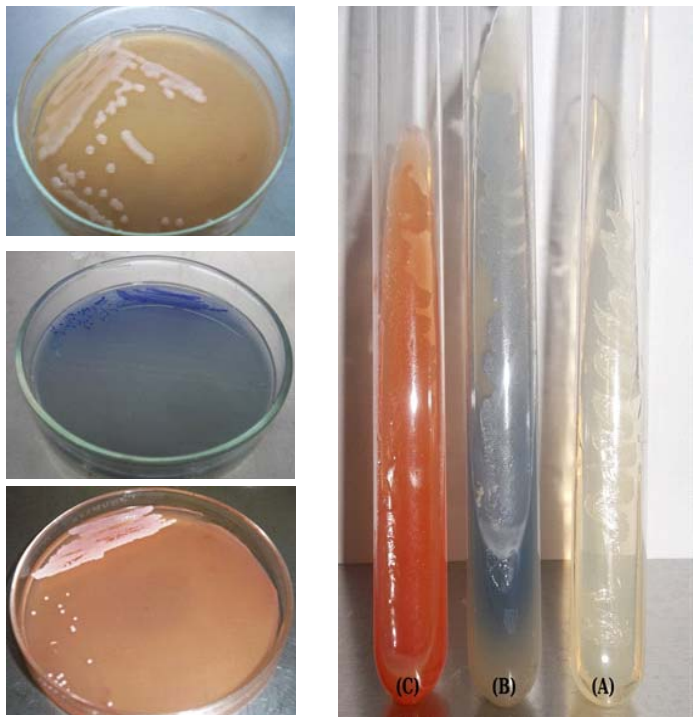

Fig. 1. Growing of Paenibacillus sp.NBR-10 on (A): Nutrient agar, (B) Aniline blue (B) and (C) Congo red media

\section{Characterization of Curdlan Gum Physical Characters}

Color of purified polysaccharide is white or slightly white. Solubility in alkalin: $0.2 \mathrm{~g}$ of the sample suspend in $5 \mathrm{ml}$ of water, after adding $1 \mathrm{ml}$ of $3 \mathrm{~N}$ sodium hydroxide and shake, the sample dissolved. Gel formation: $2 \%$ aqueous suspension of the sample heated in a boiling water bath for 10 min and cool soft gel is formed. Perception formation with cupric tratrate: A copious red precipitate of cuprous oxide is formed. Similar results obtained by Lee et al..$^{23}$ in identification of the purified curdlan from Agrobacterium sp.

\section{Chromatographic Examination}

The sugar composition of polysaccharide produced by Paenibacillus sp NBR-10 was examined by paper chromotography after hydrolyzing with acid, the hydrolysate of glucan gave one spot with an $\mathrm{Rf}$ value of similar to the value of the glucose unit, this implied that this

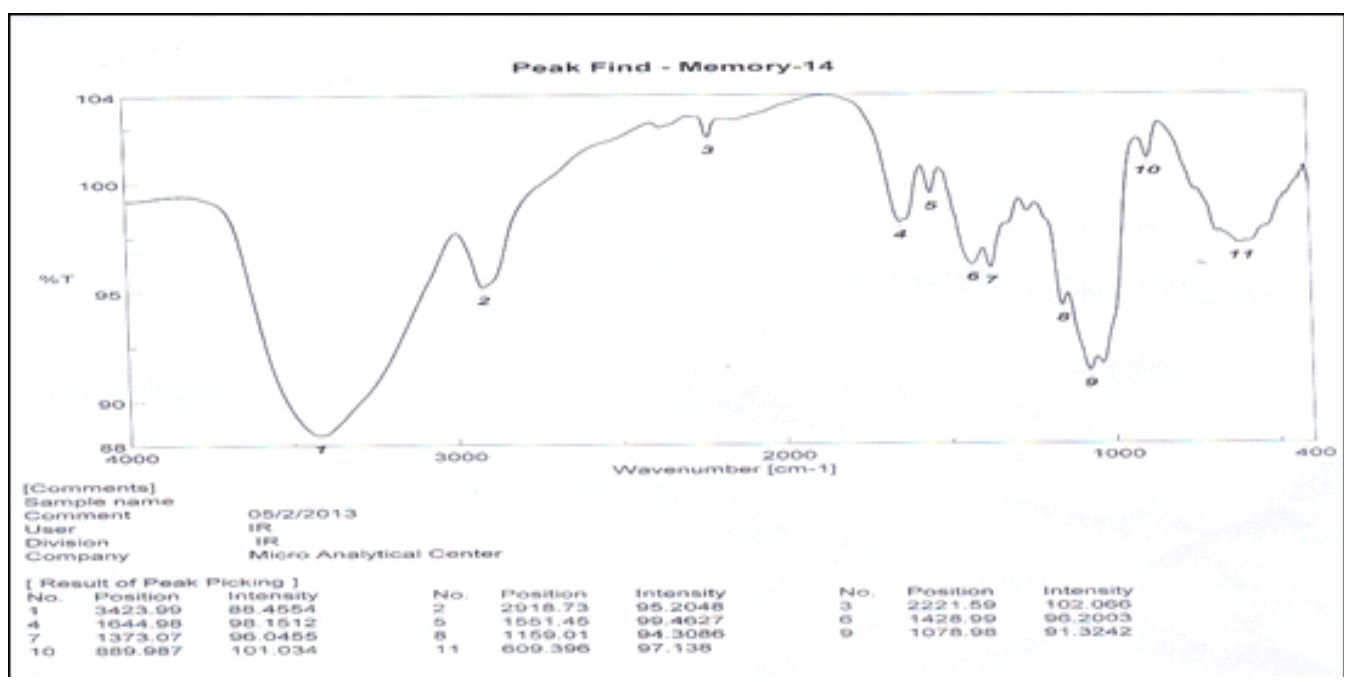

Fig. 2. FTIR-spectrum bands of curdlan produced by Paenibacillus sp. NBR-10

glucan is composed of glucose only. Similar results obtained by Jung et al. ${ }^{7}$ in identification of $\beta$-glucan produced by Paenibacillus polymyxa JB115.

\section{Spectroscopic Analysis}

The infrared absorption (FT-IR) spectrum of the purified polysaccharide in DMSO (Figure 2) showed characteristic maximum bands at: 3423.99 $\mathrm{cm}^{-1}$ which identical to presence of hydroxyl group $(\mathrm{OH})$, bands at $2918.73 \mathrm{~cm}^{-1}$ which are identical to aliphatic hydrocarbon (group $-\mathrm{CH}_{3},-\mathrm{CH}_{2}$ and -
$\mathrm{CH}$ ), and $\mathrm{C}-\mathrm{H}$ stretching, bands at $1644.98 \mathrm{~cm}^{-1}$ which identical to carbonyl group $(-\mathrm{C}=\mathrm{O})$, bands at $1428.99 \mathrm{~cm}^{-1}$ which identical to presence of ($\mathrm{C}=\mathrm{C}-\mathrm{CH}_{2}-$ ), bands at $1373.07 \mathrm{~cm}^{-1}$ which identical to presence of C-H group, and bands at $889.98 \mathrm{~cm}^{-}$ 1 identical to presence of â linked glycoside bonds. Absence of band at $840 \mathrm{~cm}^{-1}$ identical to indicated to no $\beta$ linked glycoside bonds, similar results obtained by Gayathiri et al. ${ }^{27}$ in identification of the purified curdlan from a mutant isolate of 
Agrobacterium sp. ATCC 31750.

The proton nuclear magnetic resonance spectra (H-NMR) spectrum of the purified polysaccharide was applied in DMSO-D6 at $\delta 399$ MHZ as shown in (Figure 3). H-NMR shows seven protons between $3.0 \mathrm{ppm}$ and $3.9 \mathrm{ppm}$, are attributed to the signals of the backbone chain for a $\beta$ - $(1,3)$-D glucan. The ${ }^{1} \mathrm{H}$ NMR spectrum indicates anomeric protons (4.6-5.2 ppm), sugar protons (3.0$3.9 \mathrm{ppm})$ and the signal at higher field ( $\delta 3.5)$ corresponds to â configuration of glucose. Similar results obtained by Wang ${ }^{28}$ in identification of the purified curdlan from Agrobacterium sp.

${ }^{13} \mathrm{C}$ NMR spectra (Figure 4) of polysaccharide produced by Paenibacillus sp. NBR-10 revealed six main resonances at 103.51, 73.35, 86.68, 68.88, 76.81 and $61.34 \mathrm{ppm}$, which are designed as C-1, C-2, C-3, C-4, C-5 and C-6 respectively, representing beta (1,3)-D-glucan backbone in the produced curdlan. The same result for the ${ }^{13} \mathrm{C}$ NMR spectrum of curdlan has been previously reported ${ }^{6}$. All of the above results supported that the polymer produced by Paenibacillus sp.NBR-10 was actually curdlan.

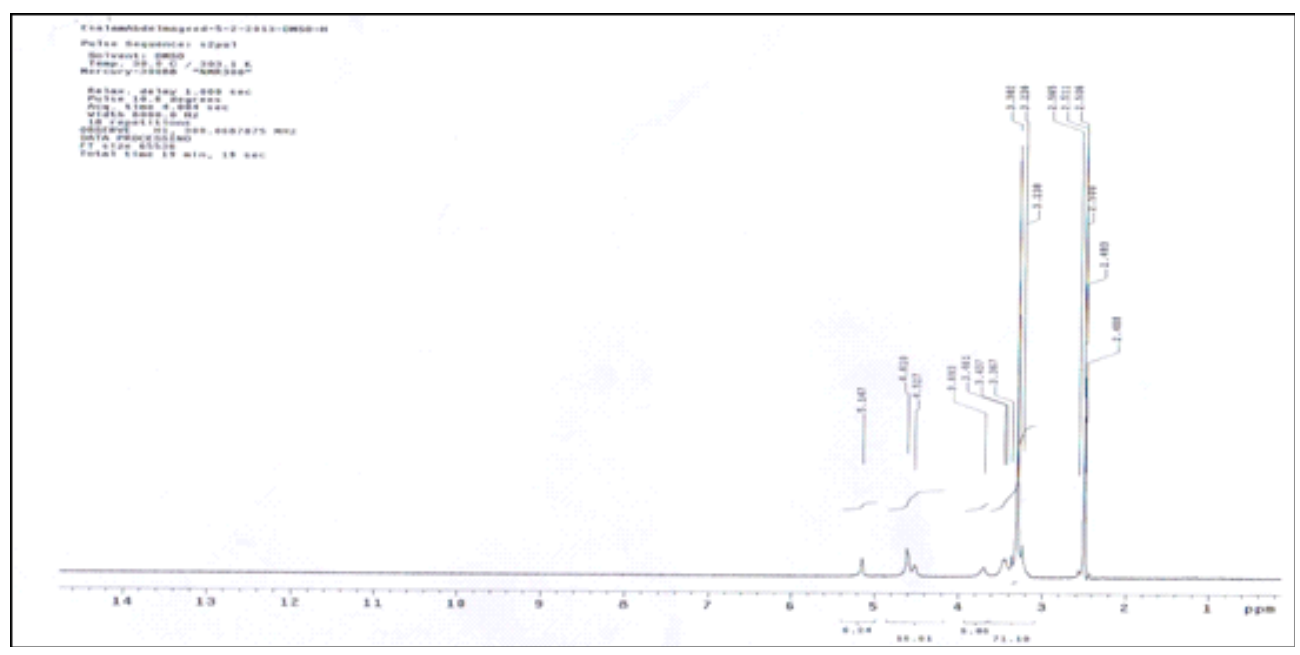

Fig. 3. HNMR-spectrum peaks of curdlan produced by Paenibacillus sp. NBR-10

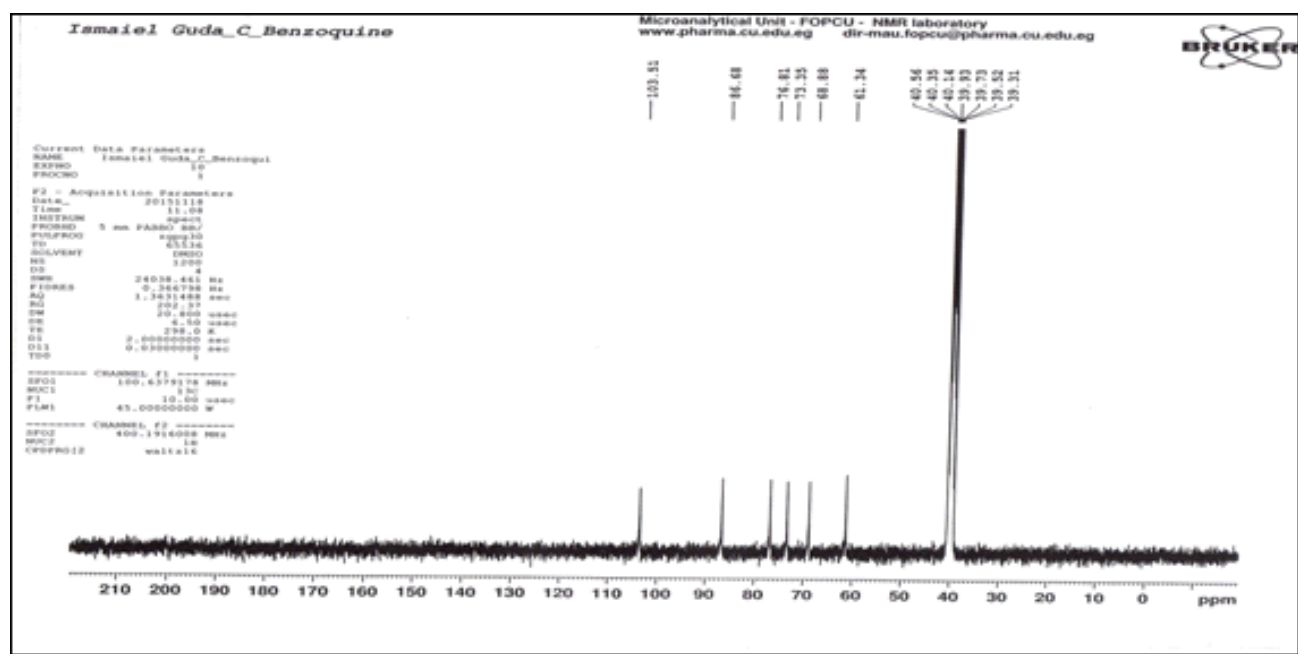

Fig. 4. ${ }^{13} \mathrm{C}$ NMR spectra of curdlan produced by Paenibacillus sp. NBR-10 


\section{CONCLUSION}

It is essential to optimize the fermentation medium for cost-effective production of curdlan. Carbon and nitrogen sources are the important nutritional components of the medium which highly influence curdlan production. As for any other microbial process, curdlan production with Paenibacillus sp. requires some specific culture conditions which become critical in order to achieve maximum productivity, many of these conditions were first experimentally adjusted at flask scale by using one-factor-at-a-time technique, this study provides a powerful tool to optimize the bioprocess in bioreactor in the future study.

\section{ACKNOWLEDGEMENTS}

Mohamed Helal El-Sayed, Hussam H. Arafat, Islam A. Elsehemy and Mona Basha are supported with the research grant No (5/1436/7/8), Deanship of Scientific Research, Northern Border University, Arar, KSA.

\section{REFERENCES}

1. Shih, I.L. Microbial exo-polysaccharides for biomedical applications. Mini. Rev. Med. Chem., 2010; 10(14): 1345-1355.

2. Harada, T., Masada, M., Fujimori, K., Maeda, I. Production of a firm resilient gel-forming polysaccharide by a mutant of Alcaligenes faecalis var mycogenes IOC3. Agric. Biol. Chem., 1996; 30: 196-198.

3. Lee, J.H., Lee, I.Y., Kim, M.K., Park, Y.H. Optimal pH control of batch processes for production of curdlan by Agrobacterium species. J. Ind. Microbiol. Biotechnol., 1999; 23(2): 143148.

4. Cui, J.D., Qiu, J.Q. Production of extracellular water-insoluble polysaccharide from Pseudomonas sp. J. Agric. Food. Chem., 2012; 60(19): 4865-71.

5. Buller, C.S., Voepel, K.C. Production and purification of an extracellular polyglucan produced by Cellulomonas flavigena strain KU. J. Ind. Microbiol., 1990; 5(2): 139-146.

6. Rafigh, S.M., Yazdi, A.V., Vossoughi, M., Safekordi, A.A., Ardjmand, M. Optimization of culture medium and modeling of curdlan production from Paenibacillus polymyxa by RSM and ANN. Int. J. Biol. Macromolec., 2014; 70: 463-473.
7. Jung, H.K., Hong, J.H., Park, S.C., Park, B.K., Nam, D.H., Kim, S.D. Production and physicochemical characterization of $\beta$-glucan produced by Paenibacillus polymyxa JB115. Biotechnol. Bioproc. Eng., 2007; 12(6): 713719.

8. Ash, C., Priest, F.G., Collins, M.D. Molecular identification of rRNA group 3 bacilli (Ash, Farrow, Wallbanks and Collins) using a PCR probe test. Proposal for the creation of a new genus Paenibacillus. Antonie Van Leeuwenhoek, 1993; 64(3-4): 253-260.

9. Raza, W., Makeen, K., Wang, Y., Xu, Y., Qirong, S. Optimization, purification, characterization and antioxidant activity of an extracellular polysaccharide produced by Paenibacillus polymyxa SQR-21. Bioresour. Technol., 2011; 102(10): 6095-6103.

10. Liang, T.W., Wu, C.C., Cheng, W.T., Chen, Y.C., Wang, C.L., Wang, I.L., Wang, S.L. Exopolysaccharides and antimicrobial biosurfactants produced by Paenibacillus macerans TKU029. Appl. Biochem. Biotechnol., 2014; 172(2): 933-950.

11. Divyasri, D., Gunasekar, V., Benny, S., Ponnusami V. A review on industrial applications of curdlan. Int. J. ChemTech Res., 2014; 6(5): 3000-3003.

12. Shih, I., Yu, J., Hsieh, C., Wu, J. Production and characterization of curdlan by Agrobacterium sp. Biochem. Eng. J., 2009; 43: 33-40.

13. Kim, I.Y., Rye, K.E., Choi W.A., Rhee Y.H. , Lee I.Y. Enhanced production of $\beta$-1,3-D-glucan by a mutant strain of Agrobacterium species. Biochem. Eng. J., 2003; 16:163-168.

14. Moscovici, M., Ionescu, C., Caraiani, T., Cric, M., Claudia, M., Chescu,V., Ghera, G., Gheorghiu, C., Stan, A., Soare, M., Mardale, R. Curdlan- type polysaccharide obtained using a strain of Agrobacterium rhizogenes. Rom. Biotechnol. Lett., 2009; 14: 4530-4537.

15. Kai, A., Ishino, T., Arashida, T., Hatanaka, K., Akaike, T., Matsuzaki, K., Kaneko, Y., Mimura, T. Biosynthesis of curdlan from culture media containing 13C-labeled glucose as the carbon source. Carbohydr. Res., 1993; 24: 153-159.

16. Nakanishi, I., Kimura, K., Kushi, S., Yamazaki, E. Complex formation of gel-forming bacterial (l-3)-Beta-D-g1ucans (curdlan-type polysaccharides) with dyes in aqueous solution. Carbohydr. Res.,1974; 32: 47-52.

17. Jiang, L. Effect of nitrogen source on curdlan production by Alcaligenes faecalis ATCC 31749. Int. J. Biol. Macromol., 2013; 52: 218- 220.

18. Yu, L., Wu, J., Liu, J., Zhan, X., Zheng, Z., Lin, C.C. Enhanced curdlan production in 
Agrobacterium sp. ATCC 31749 by addition of low-polyphosphates. Biotechnol. Bioproc. Eng., 2011; 16(1): 34-41.

19. Jung D.Y., Cho Y.S., Chung C.H., Jung D.I., Kim K., Lee J.W. Improved production of curdlan with concentrated cells of Agrobacterium sp. Biotechnol. Bioproc. Eng., 2001; 6(2): 107-111.

20. Roy, M.A., Sasser M. A medium selective for Agrobacterium tumefaciens biotype 3 . Phytopath., 1983; 73: 810.

21. West, T.P. Effect of yeast extract supplementation on curdlan production from condensed corn distillers solubles. Res. J. Microbiol., 2009; 4: 202-207.

22. Kim, M.K., Lee, I.Y., Lee, J.H., Kim, K.T., Rhee, Y.H., Park, Y.H. Residual phosphate concentration under nitrogen-limiting conditions regulates curdlan production in Agrobacterium species. J. Ind. Microbiol. Biotechnol., 2000; 25: 180-183.

23. Lee I.Y., Seo W.T., Kim G.J., Kim M.K., Ahn S.G., Kwon G.S., Park Y.H. Optimization of fermentation conditions for production of exopolysaccharide by Bacillus polymyxa. Bioproc. Eng. 1997; 16: 71-75.

24. Bull, A.T., Bushell, M.E. Environmental control of fungal growth. In: Smith JE, Berry DR, editors. The Filamentous Fungi vol. 2. London: Edward Arnold; 1976; 1-31.

25. Aiba, S., Humphrey, A.E., Millis, N.F. Biochemical Engineering. $2^{\text {nd }}$ Edition, New York: Academic Press, 1973; 92-127.

26. Gummadi, S., Kumar, K. Production of extracellular water insoluble $\beta$-1,3-glucan (curdlan) from Bacillus sp. SNC07. Biotechnol. Bioproc. Eng., 2005; 10(6): 546-551.

27. Gayathiri, T.K., Mukesh, D., Sathyanarayana, N.G. Production and downstream processing of $(1,3)-\beta$ - D-glucan from mutant strain of Agrobacterium sp. ATCC 31750. AMB Express, 2012; 2: 31.

28. Wang C.L., Huang T.H., Liang T.W., Fang C.Y., Wang S.L. Production and characterization of exopolysaccharides and antioxidant from Paenibacillus sp.TKU023. N. Biotechnol., 2011; 28(6):559-565. 